\title{
Development of Materials and Evaluation Methods for PEFCs
}

\author{
Yoshio TAKasu, ${ }^{*}$ Wataru SugImoto, ${ }^{\text {a }}$ and Masaru Yoshitake ${ }^{b}$ \\ ${ }^{a}$ Department of Fine Materials Engineering, Faculty of Textile Science and Technology, Shinshu University (3-15-1 \\ Tokida, Ueda 386-8567, Japan)

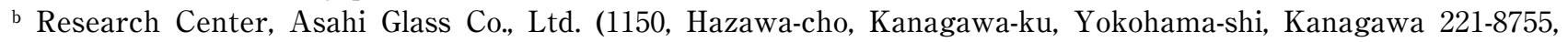 \\ Japan)
}

Received August 22, 2006 ; Accepted October 26, 2006

\begin{abstract}
This article outlines recent progress in electrocatalysts and membranes for polymer electrolyte fuel cells (PEFCs), as well as various evaluation methods for these materials, including characterization of structural and physical properties, commonly used electrochemical techniques, and advanced in situ methods. Particular attention has been paid towards matters that require consideration when using specific techniques and the uniqueness of particular evaluation methods.
\end{abstract}

Key Words : Fuel Cell, PEFC, DMFC, Electrocatalyst, Membrane

\section{Introduction}

More than 40 years has passed since Gemini-5 spacecraft blasted off into outer space with a fuel cell onboard. Now, in view of recovering the beautiful green planet Earth, fuel cell technology centers on application towards public use, from small portable devices to larger stationary mobile (automotive) systems. Prototypes of electronic devices, such as cellular phones and laptop computers powered by fuel cells, have been released and some of us who are lucky enough have already had a chance to experience vehicles or houses power-driven by fuel cells. Although fuel cells have attracted public attention from both environmental and convenience issues, its technology has not yet reached the level of the public benefit in terms of availability (cost), durability, size, and so on. Fuel cell research and development have now engulfed many scientists and engineers, establishing a typical interdisciplinary research field, where diverse viewpoints from a range of fields such as electrochemistry, catalysis, analytical chemistry, polymer science, surface science and physics have now united. ${ }^{1)}$

As one of the key materials for PEFC, membrane has controlled the performance of the development since its first space mission. The renaissance of PEFC was triggered by a new short-side-chain perfluorinated membrane and the development of PEFC systems toward commercialization has been accelerated by various new membrane technologies, such as ionomer solution technology for the drastic expansion of triple-phase interface and the remarkably stable membranes over $100^{\circ} \mathrm{C}$ under low or non humidified condition produced by the combination of polymer and electrochemical science.

This special issue was planned to gather up-to-date reports regarding new materials and characterization methods for polymer electrolyte fuel cells (PEFCs) and direct methanol fuel cells (DMFCs). In this headline, some of the key factors in materials and characterization will be described, reviewing some results of the authors on these subjects.

\section{Development of Electrocatalysts and MEAs for PEFCs ${ }^{1)}$}

\section{1 Anode catalysts}

The foremost exploited anode catalyst for PEFCs (including DMFCs) is still $\mathrm{PtRu} / \mathrm{C}$, ${ }^{2)}$ due to its tolerance to poisoning of strongly adsorbed $\mathrm{CO}$ species on Pt. The promotional role of ruthenium in the $\mathrm{PtRu} / \mathrm{C}$ catalysts is often discussed based on the "bifunctional mechanism"3) or the "ligand effect mechanism". ${ }^{4}$ The activity and durability of the $\mathrm{PtRu} / \mathrm{C}$ alloy catalyst is still inadequate; advanced anode catalysts such as ternary and quaternary alloys are being widely considered.,6) For instance, a well-alloyed $\mathrm{PtRuRh} / \mathrm{C}$ catalyst has been developed which exhibit higher activity than the $\mathrm{Pt}_{1} \mathrm{Ru}_{1} / \mathrm{C}$ (45 mass\%) catalyst which has been on the market. ${ }^{7}$

The size effect observed for the oxidation of hydrogen, methanol, formaldehyde, formic acid, acetaldehyde and carbon monoxide on $\mathrm{Pd}$ or $\mathrm{Pt}$ catalysts must relate to such changes in the valence band structure with metal particle size. ${ }^{8,9)}$

In order to enhance the catalytic activity, various oxides have also been evaluated as additives or used as the supporting materials for the catalyst metal particles. Although some research groups have reported positive effects, others denied the existence of such effects. Such discrepancy should be clarified using well-characterized oxides. In a recent study, the effect of the addition of protonated ruthenium oxide nanosheets (HROns) ${ }^{10)}$ to a $\mathrm{Pt} / \mathrm{C}$ catalyst has shown enhanced CO-tolerance and methanol oxidation properties. ${ }^{11)}$

Development of new polymer electrolytes that can be used at medium-range temperature $\left(e . g .160^{\circ} \mathrm{C}\right)$ is also a hot topic, since CO-poisoning would no longer be a serious problem at such elevated temperature. Besides the need to improve the intrinsic activity of the anode catalyst, another critical problem for the $\mathrm{PtRu} / \mathrm{C}$ catalyst is 
the degradation of the catalyst due to ruthenium dissolution during fuel cell operation, which also results in membrane failure. Studies to decrease the amount of $\mathrm{Pt}$ in the catalysts layer as well as the search for Pt-free anode catalysts are also under investigation.

\section{2 Cathode catalysts}

Typical cathode catalyst for PEFCs is $\mathrm{Pt} / \mathrm{C}$ due to its high activity towards oxygen reduction. However, further enhancement of both catalytic activity and durability is inevitable for practical use. The overpotential for oxygen reduction needs to be reduced, and the dissolution of platinum has to be minimized. Various approaches have been conducted to overcome these problems; alloying of platinum with other metals, modification of carbons, and seeking for other compounds including oxides, carbides, nitrides, silicides, metal complexes, etc. The $\mathrm{PtCo} / \mathrm{C}$ binary catalyst ${ }^{12}$ has attracted recent attention due to its enhanced specific activity and durability. After dissolution of near surface cobalt atoms from PtCo nanoparticles, an active Pt-skin layer is formed, which stabilized the inner PtCo core. ${ }^{13)}$ The inner cobalt atoms are thought to enhance the catalytic activity of the oxygen reduction on the skin platinum surface of the catalyst particles by the ligand effect. The "size effect" 8,9,14-16) of the catalysts on the catalytic activity for the reduction of oxygen is a point that needs to be considered. The search for Pt-free cathode catalyst is also important for the practical spread of PEFCs. Figure 1 shows a linear sweep voltammogram of an $\mathrm{IrO}_{2} / \mathrm{Ti}$ electrode with oxygen bubbling into a sulfuric acid solution at $60^{\circ} \mathrm{C} . .^{17}$ ) It must be noted that the onset potential for the oxygen reduction is considerably high, around $0.8 \mathrm{~V}$ vs. reversible hydrogen electrode (RHE). Although these and other numerous studies have contributed deeply to the development of PEFC and DMFC, work is still needed to improve both activity and durability, especially for fuel cell vehicle (FCV) applications. Considerable progress in characterization techniques for the electrochemical processes and physical properties of catalysts as well as advanced computer simulation techniques are expected to reveal novel less-expensive ${ }^{18)}$ and active electrocatalysts in the near future.

\section{3 MEAs ${ }^{1)}$}

The fabrication of Membrane Electrode Assembries

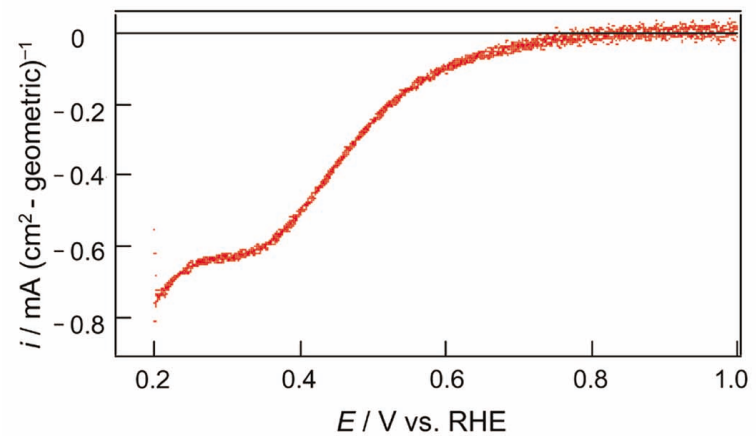

Fig. 1 Polarization curve of an $\mathrm{IrO}_{2} / \mathrm{Ti}$ electrode in $\mathrm{O}_{2}$ saturated $0.5 \mathrm{M} \mathrm{H}_{2} \mathrm{SO}_{4}$ at $60{ }^{\circ} \mathrm{C}$ at $5 \mathrm{mV} \mathrm{s}^{-1}$. The $\mathrm{IrO}_{2} / \mathrm{Ti}$ electrode was prepared by a dip-coating method. ${ }^{17)}$
(MEAs) is extremely technological and the "art" and "skill" of MEA construction often affect the overall performance of the fuel cell. In the catalyst layer, the transport of gaseous species, protons and electrons must be assured so that the formation of the "triple-phase boundary", one of the key points in cell performance, is maximized. Thus, various parameters such as the thickness of the catalyst layers and membrane, ionomer content in the catalyst layer, and fabrication pressure and temperature, need to be optimized and are often based on nondisclosed know-how. New MEA preparation methods have also been considered, for example, electrophoretic deposition of catalyst particles directly onto membranes. ${ }^{19)}$ Computer simulation and modeling of mass transport in the MEAs is also expected to be a powerful tool.

\section{Evaluation Methods for Electrode Performance ${ }^{20)}$}

\section{1 Characterization of Catalysts}

Numerous methods have been developed for the characterization of catalysts, and some of them have successfully been adopted to clarify the property of electrocatalysts. In Table 1, factors affecting the characteristics of electrocatalysts of fuel cells are listed with principal characterization techniques shown in parentheses. Some of them will be reviewed in this section.

\section{1. 1 TEM and SEM Both transmission electron} microscopy (TEM) and high-resolution scanning electron microscopy (HR-SEM) are widely used to evaluate the dispersion state of catalyst metal particles on supporting materials, typically carbon blacks. Observation of at least a few hundred particles is recommended to guarantee the evaluation of the size distribution and the mean particle size. Recent improvement of the resolution of SEM has lead to the uncomplicated observation of particles in the nanometer scale. Figure 2 shows an HRSEM image of a typical PtRu/C catalyst. Observation using HR-SEM is less-laborious compared to TEM, and the "back-side" of the carbon support is not detected. Larger particles are sometimes observed with smaller ultrafine particles; therefore, small area observation at high magnification should be followed by a larger area observation at low magnification in the same region. ${ }^{21}$ Inspection of both secondary electron images and backscattering electron images when using SEM is recommended to differentiate between metal nanoparticles and support material. TEM is of course more suitable for high resolution imaging, especially on the atomic scale. Crystallinity, facets, and detailed particle shape are information that cannot be obtained by HR-SEM. Inspection of both bright-field and dark-field imaging using TEM is also recommended. Scanning transmission electron microscopy (STEM) combined with energy dispersive X-ray analyzer (EDX) shows its validity especially for the characterization of alloy catalysts such as $\mathrm{PtRu} / \mathrm{C}$ in the single-particle scale. The development of 3-D reconstruction imaging is also a powerful tool for visualization of supported catalysts and MEAs. $^{22)}$ 
Table 1 Factors affecting the characteristics of electrocatalysts of fuel cells and the characterization methods.

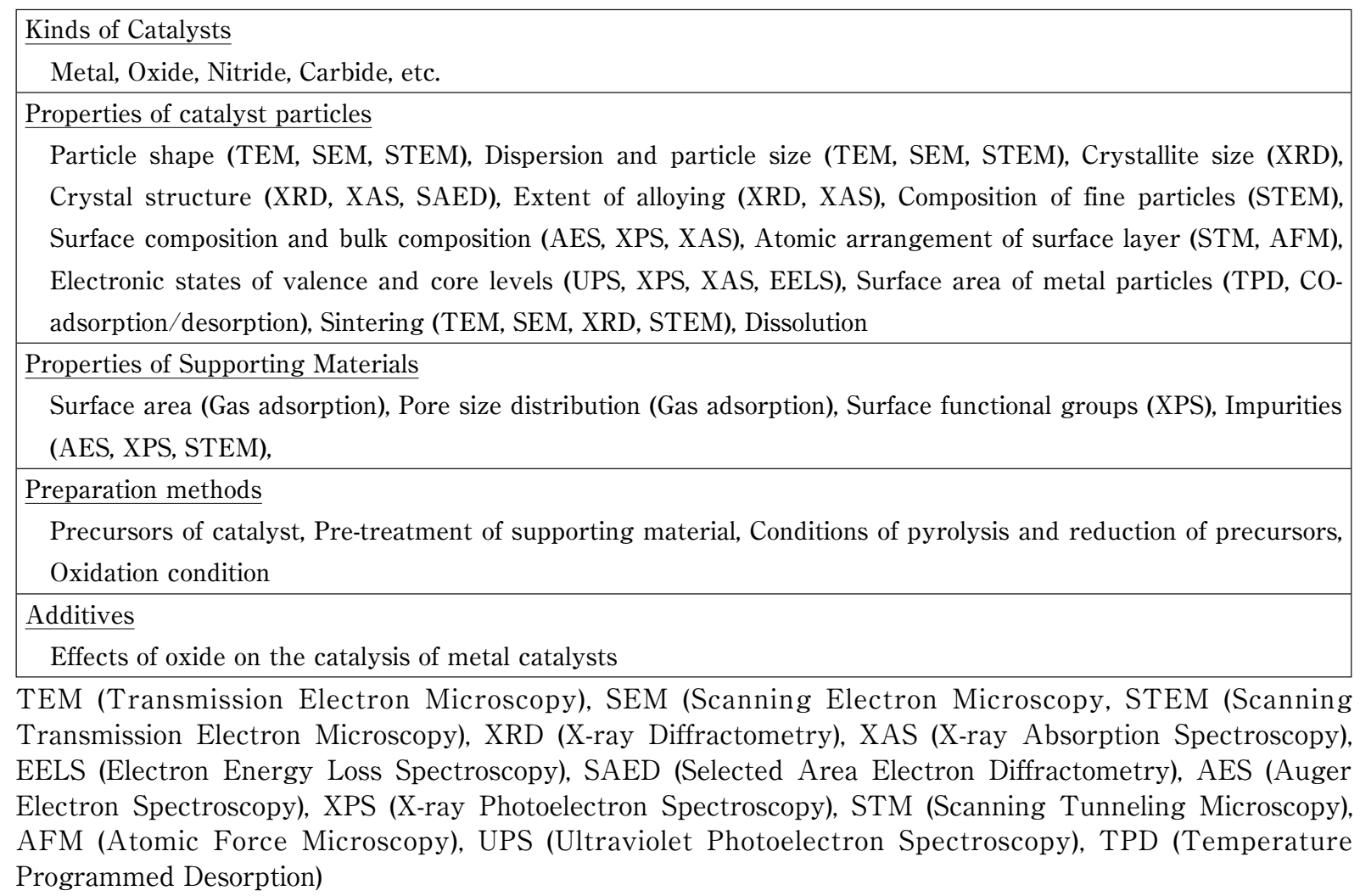

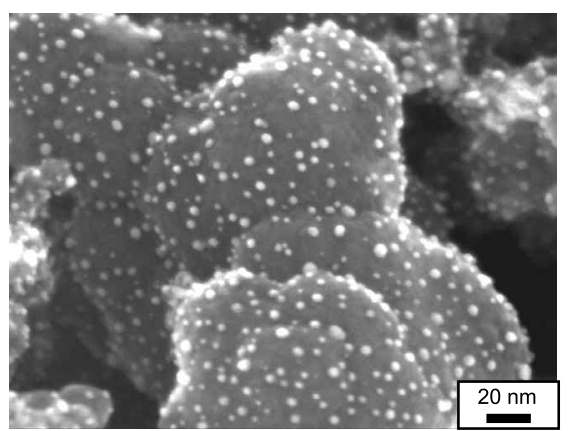

Fig. 2 HR-SEM image of a $\mathrm{Pt}_{50} \mathrm{Ru}_{50} / \mathrm{C}$ (30 mass\%) catalyst prepared from ethanolic solutions of $\mathrm{Pt}\left(\mathrm{NH}_{3}\right)_{2}\left(\mathrm{NO}_{2}\right)_{2}$ and $\mathrm{Ru}\left(\mathrm{NO}_{3}\right)_{3}$ and carbon black support (Vulcan XC-72R).

\section{1. 2 XRD X-ray diffraction analysis (XRD) is a} conventional but useful technique for the characterization of the crystallite size, extent of alloying, crystallinity, etc. The crystallite size of metal catalysts can be easily calculated using the Scherrer equation, though such analysis should be used in combination with particle size of TEM or HR-SEM images. If the distribution of the particle size is multi-modal, the diffraction peaks need to be appropriately deconvoluted. The use of Scherrer equation should be conducted with care in the case of alloy particles such as $\mathrm{PtRu} / \mathrm{C}$ catalysts; various parameters such as the extent of alloying, homogeneity, particle shape, etc. will influence the diffraction peaks.

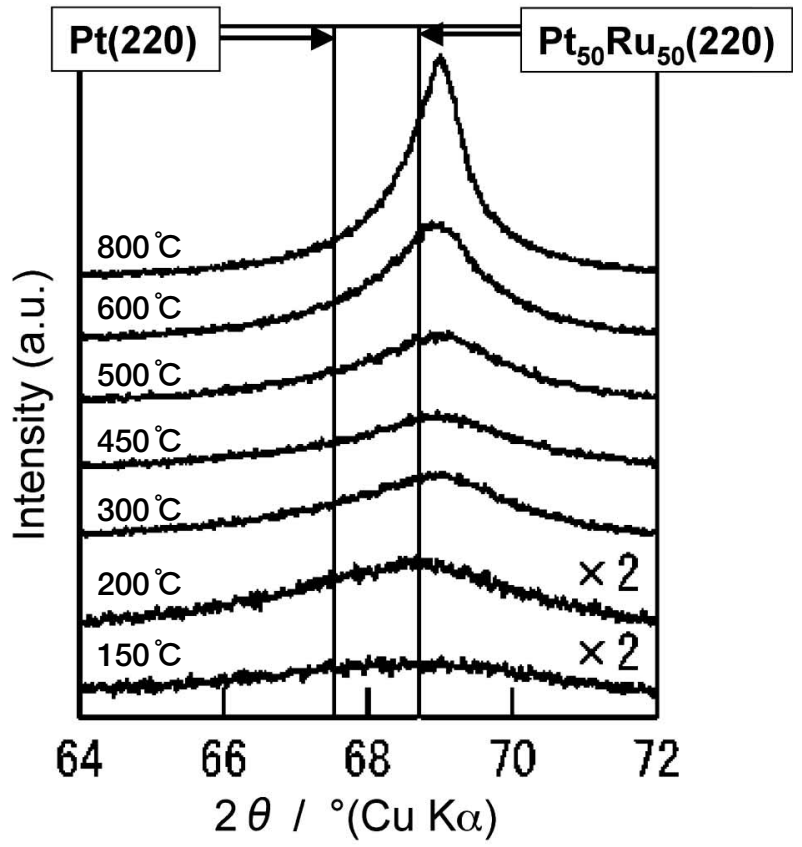

Fig. 3 X-ray diffraction patterns of $\mathrm{Pt}_{50} \mathrm{Ru}_{50} / \mathrm{C}$ catalysts pyrolyzed at various temperatures. The values on each XRD spectra present the heat-treatment temperature of the $\mathrm{Pt}_{50} \mathrm{Ru}_{50} / \mathrm{C}$ catalysts in a stream of $\mathrm{H}_{2}(10 \%)+$ $\mathrm{N}_{2}(90 \%)^{23)}$

Figure 3 shows the X-ray diffraction patterns of $\mathrm{Pt}_{50} \mathrm{Ru}_{50} / \mathrm{C}$ catalyst pyrolyzed under reducing condition at various temperatures. The XRD peak sharpens with 
increasing pyrolysis temperature, especially above $600{ }^{\circ} \mathrm{C}$, suggesting an increase in the crystallite size and/or an increase in crystallinity. With increasing pyrolysis temperature from 150 to $450{ }^{\circ} \mathrm{C}$, the fcc $(220)$ peak shifts to higher diffraction angle, suggesting that greater amounts of Ru were introduced into the fcc structure. ${ }^{23)}$

\section{1. 3 XPS and UPS X-ray photoelectron} spectroscopy (XPS) is useful to obtain the surface composition and oxidation state of surface species, thus has widely been adopted for the characterization of electrocatalysts. XPS provides a rough estimation of the surface composition or analysis of a sample if the surface is insensitive to exposure to air. For surface analysis, one should pay attention not only to the escape depth of photoelectrons from the sample, which depends on their kinetic energy, but also to the surface oxidation induced by exposure to atmosphere before setting the sample into the XPS chamber. In the case of alloy catalysts, removal of surface contamination by ion bombardment may lead to a change in the real surface composition via selective sputtering of the surface atoms. In situ experiments are favorable in order to avoid any contamination or oxidation. The model catalyst method using flat carbon substrates has been adoptable for XPS and the ultraviolet photoelectron spectroscopy (UPS). The size effect of the valence band structure near the Fermi level of ultrafine palladium particles on graphite has clearly been shown in the UPS(He II) in Fig. 4..$^{24,25)}$ That is, the center of the density of state shifts to the higher binding energy with decreasing Pd particle size. The size effects observed for various reactions on Pd or Pt catalysts must relate to such changes in the valence band structure with metal particle size., ${ }^{8,14)}$

\section{2 Preparation of test electrodes}

\section{2. 1 Model catalyst methods}

After Clavilier proposed a simple method to prepare single crystal electrodes, ${ }^{26)}$ single crystal electrodes have been widely
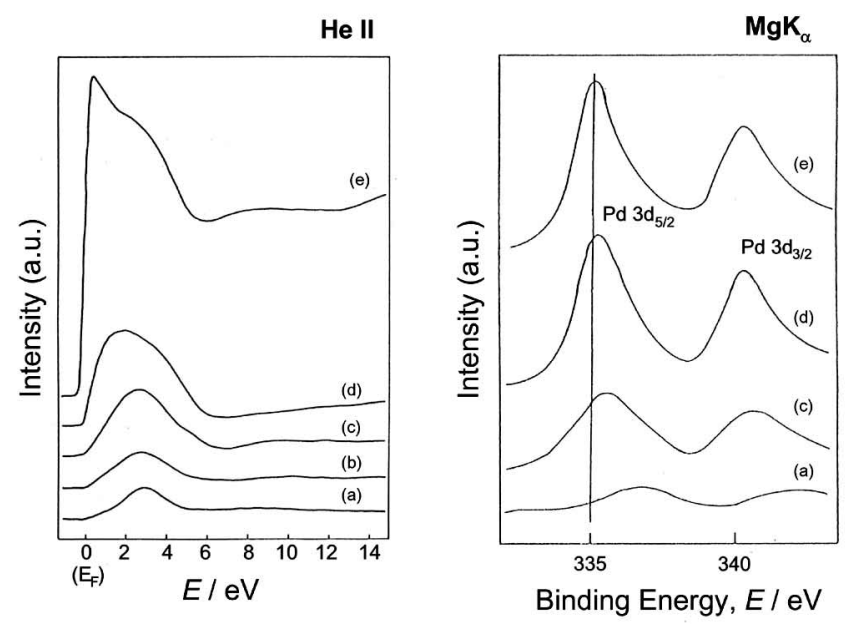

Fig. 4 Photoelectron spectra of the valence band (left) and core level (right) of Pd nanoparticles embedded on a graphite plate by vacuum evaporation. Approximate mean size of Pd particles: (a); $1 \mathrm{~nm}$, (b); $2 \mathrm{~nm}$, (c); $4 \mathrm{~nm}$, (d); $5.3 \mathrm{~nm}$, (e); almost continuous film. ${ }^{25)}$ used for fundamental studies. Research on the oxidation behavior of hydrogen, carbon monoxide, methanol and methanol-related species on single crystal electrodes have contributed considerably to the understanding of the catalytic processes on metal catalysts.

The model catalyst electrode method has been proposed to cover the wide gap between single crystal electrodes and practical electrodes. ${ }^{27)}$ A conceptional drawing of the model catalyst Pt/GC (GC: Glassy Carbon) and a SEM image are shown in Fig. 5. With a model catalyst consisting of platinum nanoparticles finely dispersed on a mirror-polished GC, the catalytic activity per real surface area of Pt particles for the oxidation of methanol in $0.5 \mathrm{M}$ $\mathrm{H}_{2} \mathrm{SO}_{4}$ was found to decrease with a decrease in the $\mathrm{Pt}$ particle size at both 0.5 and at $20 \mathrm{~min}$ after the polarization of the electrode at $0.5 \mathrm{~V}$ vs. RHE. ${ }^{28)}$ The strong points of this model electrode are that there is no need to use a binder such as ionomer and the catalysis is not influenced by the pore structure of the support.

3. 2. 2 Thin film electrode method Although final testing of the performance of electrocatalysts needs to be carried out with MEAs, preliminary screening tests and evaluation of the intrinsic activity of catalysts is often conducted using microgram scale electrodes prepared by the so-called thin film electrode method proposed by Schmidt et al. ${ }^{29)}$ This method can cover the gap between the model electrodes and MEA catalyst layer. In contrast to the catalysts layer in MEAs, a homogeneous dispersion of the catalyst particles is deposited on a polished flat GC surface and is affixed with a thin layer of cast ionomer. The catalyst dispersion state and thickness of the cast ionomer film is particularly important to attain reproducibility of the electrocatalytic performance, especially in the case of cathode activity. ${ }^{30)}$

\section{3 Electrochemical techniques ${ }^{20)}$}

Various electrochemical methods have been developed to characterize electrocatalysts (Table 2). A few results obtained using some of them will be reviewed in this section.
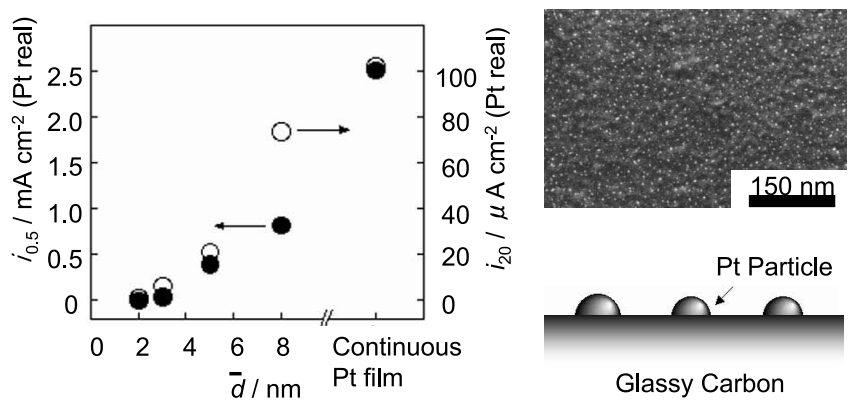

Fig. 5 The size effect of metal particles clarified by the Pt/GC model catalyst electrodes. The current shows the chronoamperometry at $0.5\left(i_{0.5}\right)$ and $20\left(i_{20}\right)$ min after polarization at $0.5 \mathrm{~V}$ vs. RHE per real surface area of $\mathrm{Pt}$ particles for the oxidation of methanol in $0.5 \mathrm{M} \mathrm{H}_{2} \mathrm{SO}_{4}+$ $1 \mathrm{M} \mathrm{CH}{ }_{3} \mathrm{OH}$ at $60{ }^{\circ} \mathrm{C} .{ }^{28)}$ A conceptional drawing of the model catalyst is shown at the right-hand with the HRSEM image. 
Table 2 Principal electrochemical characterization methods of electrocatalysts.

\begin{tabular}{|l|}
\hline$\frac{\text { Catalytic activity and polarization }}{\text { (Quasi)-state method (I-E), CV, LSV, RDE, RRDE, CFDE, EIS }}$ \\
\hline$\frac{\text { Active surface area of metal catalyst }}{\text { CO-striping voltammetry, CV }}$ \\
\hline$\frac{\text { Components of resistance }}{\text { EIS }}$ \\
\hline$\frac{\text { Adsorbed species }}{\text { Adsorbed species and adsorbed state (IRAS, FTIRAS), Amount of adsorbed species (EQCM) }}$ \\
\hline$\frac{\text { Products }}{\text { DEMS }}$ \\
\hline
\end{tabular}

CV (Cyclic Voltammetry), LSV (Linear Sweep Voltammetry), RDE (Rotating Disc Electrode Method), RRDE (Rotating Ring Disc Electrode Method), CFDE (Channel Flow Disc Electrode method), EIS (Electrochemical Impedance Spectroscopy), EQCM (Electrochemical Quartz Crystal Microbalance), IRAS (Infra-red Absorption Spectroscopy), FTIRAS (Fourier Transformed Infra-red Absorption Spectroscopy), DEMS (Differential Electrochemical Mass Spectrometry)

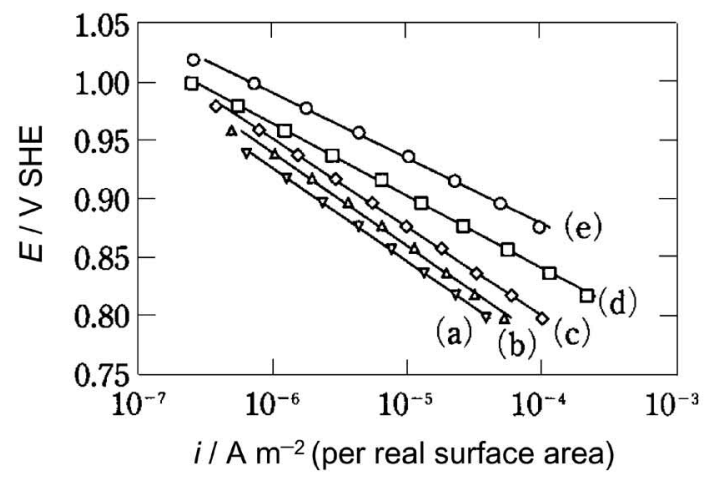

Fig. 6 Tafel plots for the reduction of oxygen on the $\mathrm{Pt} / \mathrm{GC}$ mode catalyst electrodes in $5 \mathrm{mM} \mathrm{HClO}_{4}$ at $25^{\circ} \mathrm{C}$. The mean size of Pt particles: (a); $1.2 \mathrm{~nm}$, (b); $2.7 \mathrm{~nm}$, (c); $3.7 \mathrm{~nm},(\mathrm{e}) ; 5.3 \mathrm{~nm}^{14)}$

\section{3. 1 Quasi-steadt state $I-E$ measurement Measure-} ment of the quasi-steady state $I-E$ curves by chronoamperometry is the most fundamental method for the evaluation of catalytic activity. An example of the $I-E$ relationship of $\mathrm{Pt} / \mathrm{GC}$ model catalysts determined by a quasi-steady state voltammetry in $0.02 \mathrm{M} \mathrm{HClO}_{4}$ is shown in Fig. 6 for various Pt particle size. ${ }^{14)}$ Since the current density in this figure is presented with the real surface area determined by cyclic voltammetry (CV), the decrease in the current density with decreasing the $\mathrm{Pt}$ particle size, "size effect", is evident in this condition. The Tafel slope of these $I-E$ relationships also shows the existence of the "size effect" in this figure. Porous thin film electrodes and MEAs sometimes show non-linear relationships between the logarithm of current density and the electrode potential even outside the concentration overpotential region due to the complex nature of the inner resistance within the electrodes. Quantitative analysis of the inner resistance is not easily clarified even by electrochemical impedance spectroscopy (EIS) or by current interruption methods.

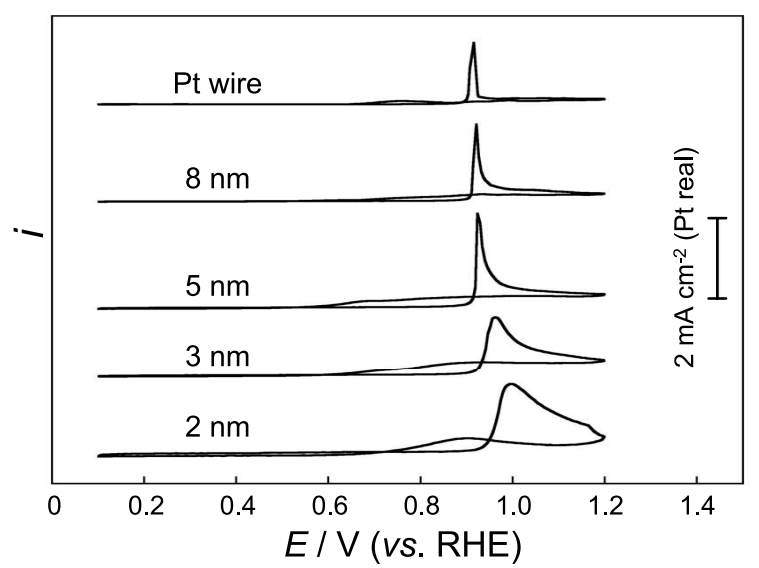

Fig. 7 Cyclic voltammograms for the oxidation of $\mathrm{CO}$ on the $\mathrm{Pt} / \mathrm{GC}$ model catalyst electrodes in $0.5 \mathrm{M} \mathrm{H}_{2} \mathrm{SO}_{4}$ at $60{ }^{\circ} \mathrm{C}$. CO gas was bubbled into the electrolyte during the polarization. The potential sweep rate was $50 \mathrm{mV} \mathrm{s}^{-1}$. The numerical values on the voltamograms present the mean size of Pt particles on GC. ${ }^{28)}$

3. 3. 2 CV and LSV Cyclic voltammetry (CV) and linear sweep voltammetry (LSV) are probably the most widely applied techniques to evaluate the non-steady state performance of fuel cell electrocatalysts. The adsorption-desorption behavior and catalytic activity can be obtained. Figure 7 shows cyclic voltammograms for the oxidation of $\mathrm{CO}$ on $\mathrm{Pt} / \mathrm{GC}$ model catalyst electrodes in $0.5 \mathrm{M} \mathrm{H}_{2} \mathrm{SO}_{4}$ at $60{ }^{\circ} \mathrm{C}$ with $\mathrm{CO}$ bubbling. ${ }^{28)}$ As shown in this figure, both the onset and peak potentials shift to higher electrode potential with a decrease in $\mathrm{Pt}$ particle size, suggesting that smaller Pt particles need higher overpotential than larger ones. An example of the LSV is shown in Fig. 8, where the effect of the addition of $\mathrm{HROns}^{10)}$ to a $\mathrm{Pt} / \mathrm{C}(\mathrm{C}$ : carbon black) catalyst for the oxidation of methanol. ${ }^{11}$ The onset potential for the oxidation of methanol of the $\mathrm{Pt} / \mathrm{C}$ catalyst is reduced by the modification with HROns, while the HROns 


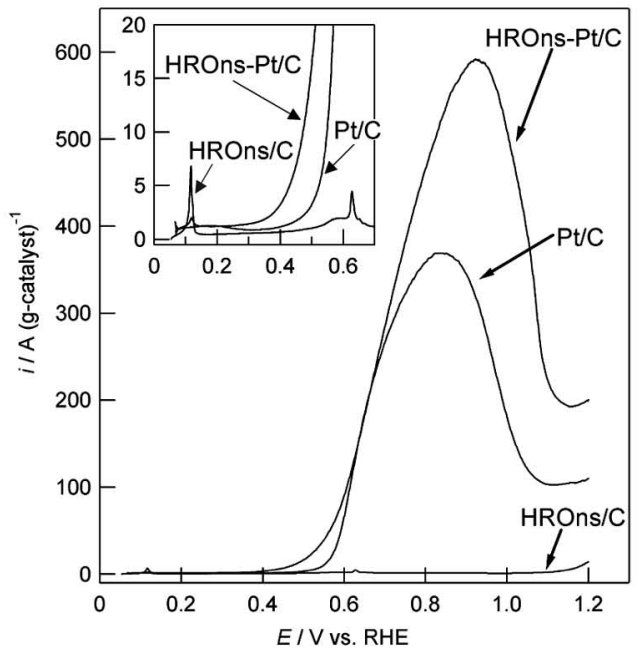

Fig. 8 Linear sweep voltammograms of $\mathrm{Pt} / \mathrm{C}$, HROns/C and HROns modified $\mathrm{Pt} / \mathrm{C}$ electrodes for the oxidation of methanol in $0.5 \mathrm{M} \mathrm{H}_{2} \mathrm{SO}_{4}+1 \mathrm{M} \mathrm{CH}_{3} \mathrm{OH}$ at $60{ }^{\circ} \mathrm{C}$. The potential sweep rate was $10 \mathrm{mV} \mathrm{s}^{-1} .^{11}$ )

themselves show no catalytic activity for the oxidation of methanol. Although these non-steady state voltammetric techniques are useful to obtain the primary information on the catalysis, the results are better to be confirmed by a (quasi-)steady state method, because the surface state of the catalyst often changes during consecutive potential sweeping.

\section{3. 3 Stripping voltammetry CO-stripping} voltammetry displays its ability both in aqueous electrolytes and in MEAs for evaluation of the COtolerance and determination of the electrochemically active surface area (real surface area) for many precious metals (Pt, Ir, Pd, Ru, Rh and their alloys). ${ }^{31-33)}$ The surface area calculated from hydrogen adsorption/desorption charge does not always reflect the real active surface area, especially when hydrogen absorption occurs. Since the amount of the adsorbed CO on the catalyst surface is influenced by both cell temperature and admission potential of $\mathrm{CO}$ adsorption, these parameters should be taken into consideration when using CO-stripping voltammetry. CO-stripping voltammetry can also be adopted for the estimation of the catalytic property of catalysts or additives on the methanol oxidation. Figure 9 shows the CO-stripping voltamograms of $\mathrm{Pt} / \mathrm{C}$, HROns and HROns modified $\mathrm{Pt} / \mathrm{C}^{9)}$ In spite of the fact that $\mathrm{CO}$ does not adsorb on the HROns, the onset potential for the oxidation of the adsorbed $\mathrm{CO}$ on the $\mathrm{Pt} / \mathrm{C}$ catalyst shifted to the lower potential. Thus, HROns may act as a promoter adding $\mathrm{OH}$ groups to oxidize the $\mathrm{CO}$ species on $\mathrm{Pt}$, resulting in the enhancement of the methanol oxidation on the catalyst. Cu-stripping has also been shown to be effective for evaluation of the surface properties, especially for alloys. ${ }^{34)}$

3. 3. 4 RDE, RRDE and CFDE ${ }^{20,35,36)}$ The rotating disk electrode method (RDE) displays its ability for the determination of the catalytic activity of electrocatalysts

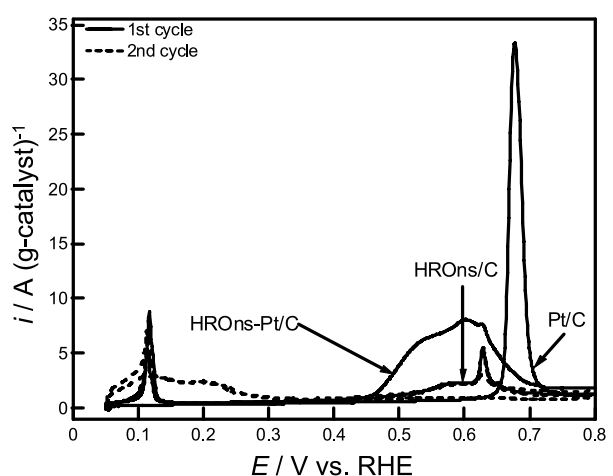

Fig. 9 CO-stripping voltamograms of $\mathrm{Pt} / \mathrm{C}$, HROns/C and HROns modified $\mathrm{Pt} / \mathrm{C}$ electrodes in $0.5 \mathrm{M} \mathrm{H}_{2} \mathrm{SO}_{4}$ at $60^{\circ} \mathrm{C}$. The potential sweep rate was $10 \mathrm{mV} \mathrm{s}^{-1.11)}$

for the oxygen reduction in aqueous electrolytic solutions, because the supply of the oxygen gas to the electrode surface is enhanced under controlled by the well defined rotation of the electrode. The kinetic current density can be obtained from RDE data acquired at various rotation speeds using the Koutecky-Levich equation. Care must be taken when determining the number of electrons transferred in the overall reduction process since the RDE method relies on the precondition that the surface is flat. The ratio of the formation of water to hydrogen peroxide during the oxygen reduction on the catalysts can be determined by the rotating ring disk electrode method (RRDE).

The channel flow double electrode (CFDE) resembles the RRDE. Since the cell is a closed system, control of the electrolyte temperature and concentration of dissolved oxygen is easier than the RRDE, in particular in the high temperature regime. Recently, Wakabayashi et al. succeeded in the analysis of the process of oxygen reduction on $\mathrm{Pt}$ and $\mathrm{Pt}$-based alloy catalysts at a wide temperature range $\left(20-90^{\circ} \mathrm{C}\right)$ by the simultaneous evaluation of the oxygen and hydrogen peroxide reduction current using a CFDE. ${ }^{36)}$

3. 3. 5 EIS ${ }^{20,37-39)}$ Electrochemical impedance spectroscopy (EIS) can provide information on the kinetics of the quasi-steady state at a given electrode potential. Appropriate fitting of EIS data can give a (semi-)quantitative assessment of the various resistive elements associated with the electrochemical reaction. It has also been applied to understanding the anodic processes for methanol oxidation in both half cell aqueous electrolytes and full cell configuration (MEAs).

It is important to design an appropriate equivalent circuit for modeling the Faradaic impedance to analyze the electrode reaction by EIS. Figure 10-(a) shows an equivalent circuit for modeling the Faradaic impedance on DMFC anodes, where $R_{\mathrm{s}}$ is the solution resistance, $C$ is the capacitance, $R_{\infty}$ is the reaction resistance of $\mathrm{CH}_{3} \mathrm{OH}$ to $\mathrm{CO}_{\mathrm{ad}}, R_{0}$ is the reaction resistance of $\mathrm{CO}_{\mathrm{ad}}$ oxidation, and $L$ is the inductance of $\mathrm{CO}_{\text {ad }}$ oxidation. ${ }^{39)}$ Since this equivalent circuit was inadequate for the high frequency range, a modified equivalent circuit shown in Fig. 10-(b) was proposed considering a charge-transfer process at 
(a)

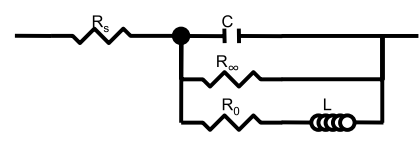

(b)

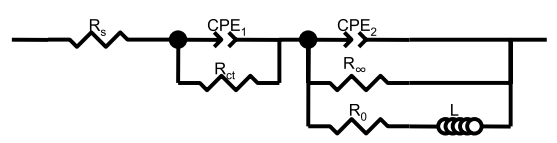

Fig. 10 (a) Equivalent circuit for modeling the Faradaic impedance on DMFC anodes. (b) Equivalent circuit for modeling the Faradaic impedance on DMFC anodes considering the high frequency impedance data. ${ }^{39)}$

the outermost surface of the porous $\mathrm{PtRu} / \mathrm{C}$ electrode. Here, $\mathrm{CPE}_{1}$ and $R_{\mathrm{ct}}$ are the frequency-dependent capacitance and the charge-transfer resistance at the outermost surface of the electrode. The $\mathrm{CPE}_{2}$ is also introduced as a constant phase element instead of a capacitor for the electric double-layer capacitance to account for the porous catalyst. This modified equivalent circuit agreed well with the experimental data for the methanol oxidation throughout the whole frequency range studied.

\section{Development of Membranes for PEFC}

\section{1 General aspects of membranes}

Perfluorinated sulfonic acid (PFSA) membranes as shown in Fig. 11 have played extremely important roles in PEFC development mainly because of their excellent chemical stability, protonic conductance and high water diffusivity in wide range of temperature caused by the these non-cross-linked structures. But they also cause decrease in mechanical strength under the condition of high water-uptake and high temperature and unnegligible methanol cross-leak at highly concentrated methanol aqueous solution. Present detailed understanding of perfluorinated membranes is summarized in the references. ${ }^{40-43)}$

Commercialization also requires materials of sufficiently matured cost. Therefore, various types of candidate electrolytes have been proposed to overcome the conventional perfluorosulfonic acid membranes as shown in

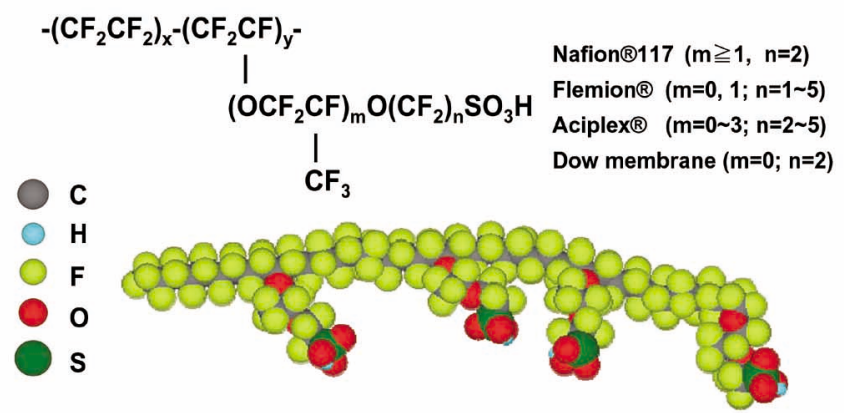

Fig. 11 General expression of PFSAs and molecular image.
Fig. 12. The strong points of the conventional perfluomembranes such as chemical stability and conductivity have been developed by stabilization of the end groups and introduction of new chemical structures. Reinforcement technology with PTFE realized the application of very thin membranes which can offer non- or low-humidification operation. Perfluoromembrane technology has given over 20,000 hours operation to $\mathrm{H}_{2}$ fuel stacks around 70 to $80^{\circ} \mathrm{C}$.

Heat-resistant plastics such as PBI which are impregnated with phosphoric acid can offer over several thousand hours operation time above $150^{\circ} \mathrm{C}$. Sulfonated hydrocarbons which have chemical structure resistant against hydrolysis showed the possibility of long term operation at temperature higher than conventional test condition. Various electrolytes comprised of porous structure such as porous Si-P-glass and porous sheet, are at the stage of basic research. Membranes for DMFC requires protonic conductance equivalent to that of perfluorosulofonic acid membranes and small cross-leak of methanol. Surface modified fluoromembranes, hydrocarbon type and electrolyte-filled porous sheets are reported to be installed to DMFC systems in portable equipments.

\section{2 Chemical degradation problem ${ }^{4-49}$}

Commercialization of PEFC systems requires high performance and low cost at once. Chemical degradation of perfluorinated membranes was realized since investigation of low humidification operation began, aiming to lower the system cost. Research to analyze and solve the degradation phenomena have now started. Basically, the degradation problem has been investigated based on the mechanism in water electrolysis proposed by LaConti, et al., where hydrogen peroxide or radicals caused by the cross-leak of hydrogen and oxygen through membrane play an important role. The old report proposed also typical design for mitigation applicable even to the present situation. Effect of catalyst layer, operation condition such as humidification, temperature on values such as protonic conductance, hydrogen leakage through membrane, fluoride ion (F-) release, molecular weight, mechanical characteristics, etc. have been investigated. Recent studies have deepened

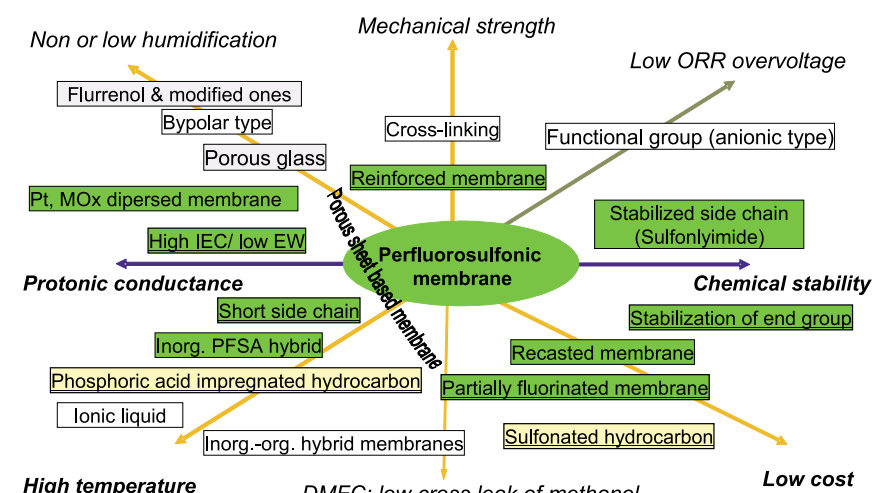

Fig. 12 Proposed candidate electrolytes for fuel cells. (Underlined electrolytes are in/after the stage of stack test level.) 
the understanding of the mechanism of formation of $\mathrm{H}_{2} \mathrm{O}_{2}$, starting sites of decomposition in membrane molecule, catalyst rearrangement in catalyst layers and membrane, etc. Various types of measures to mitigate chemical degradation have been proposed. In fact, several thousand hours operations over $100{ }^{\circ} \mathrm{C}$ under lower humidified conditions have been reported using perfluorinated sulfonic membranes.

\section{3 High temperature membrane}

Operation over $100{ }^{\circ} \mathrm{C}$ may render many merits such as easier emission of formed heat, higher resistance to CO poisoning, and better thermal utilization to PEFC systems. Introduction of reinforcement technology, new chemical structures such as shorter side chain or bulky unit in main chain repressed the creepage phenomena and raised the operation temperature of perfluorinated membranes. Hybridization with hydrophilic inorganic materials was studied for high temperature operation. Radical scavenging technology is expected to increase easier operation at higher temperature.

Hydrocarbon type membranes have been investigated as one of the major alternative systems mainly in the state of sulfonated compounds or phosphoric acid bearing systems. Tolerance against hydrolysis is one of the major factors for high temperature membranes.

PBI (polybenzimidazole)-type membranes impregnated with phosphoric acid can offer non-humidification operation at $160{ }^{\circ} \mathrm{C}$ but these membranes cannot be applicable to continuous operation below $100{ }^{\circ} \mathrm{C}$. Dissolubility with sufficient protonic conductance is the first checkpoint in the study of sulfonated type membranes. Derivatives of poly-ether ether ketone (PEEK), poly-arylene ether (PSF), polyimide (PI), polyphosphazene, etc. have been investigated as typical potentially attractive candidates. Although most of them are attacked by Fenton reagents more seriously than perfluorocompounds, some of them were reported to be able to offer long term cell operation in their own way. Low cross-leakage of gases through membranes caused by their structure may be one of the reasons. One more issue is to get good adhesion between membrane and catalyst layers in hydrocarbon systems. Some sulfonated polymer of aromatic polymer is reported to be installed into FCV.

\section{4 Membranes for DMFC ${ }^{50,51)}$}

Methanol cross-leak which is caused by protonic drag of methanol is one of the primary issues. Membranes with cross-linked structure, hybrid types based on porous structure, anionic membrane have been investigated. Membranes with methanol cross leakage of under $3 / 10$ of Nafion are installed to portable uses. New membranes with further reduced methanol permeability are essential.

\section{Evaluation Methods for Membrane Performances}

Some of properties of electrolyte membrane related with PEFC such as ion exchange capacity (IEC) or equivalent weight $(\mathrm{EW})$, molecular weight (MW) or corresponding parameter, water uptake after immersion in water, gas permeability and mechanical properties in dry state, etc. can be evaluated based on conventional procedures, but many of them have required the introduction of new techniques or creation of new measurement protocols suitable for a working fuel cell of various expected applications. As a matter of fact, it has been claimed and requested by many concerned to standardize common measuring procedures and some protocols were proposed in NEDO's PEFC programs. ${ }^{52}$ IEC or EW, MW and solvent uptake in water containing solution are the basic properties to be measured just before advanced evaluation. Properties such as water uptake, proton conductivity, water transport, gas permeation, dimensional stability, mechanical strength, compressive properties, creep properties, chemical stability are usually evaluated in the atmosphere of controlled temperature and humidity. Pretreatment of membranes before test is important for reproducible experimental result.

More advanced analytical methods have to come to be required to understand more detailed behaviors. ${ }^{20)}$ For example, many researchers have been reported around 20 to $30 \%$ from $\mathrm{CV}$ measurement in $\mathrm{N}_{2}$ atmosphere as $\mathrm{Pt}$ utilization in MEA are strongly dependent on preparation procedure using catalyst ink comprised of catalyst and ionomer dispersion. Trial measurements such as observation of ionomer on catalyst particles in MEA by

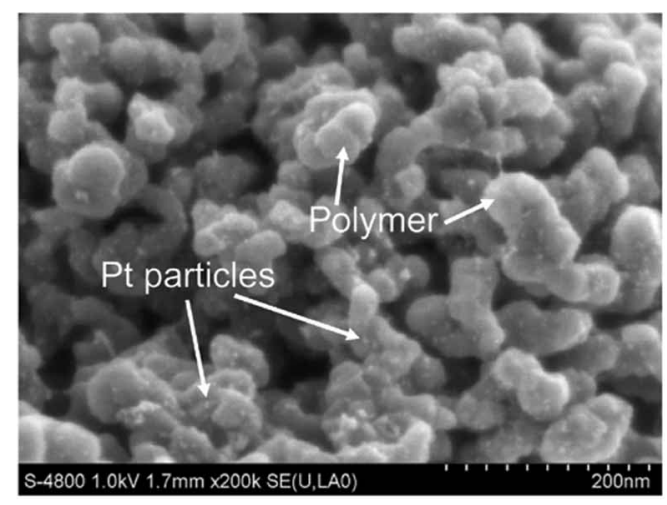

(a)

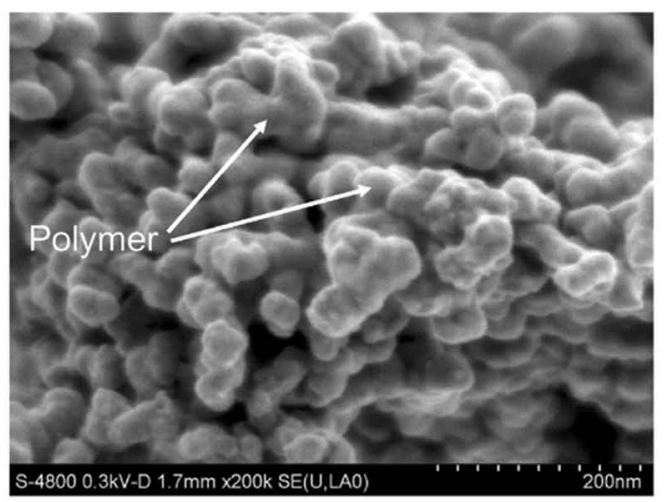

(b)

Fig. 13 FE-SEM images of a MEA surface. (a) ACV $=1$ $\mathrm{kV}$. Some parts of catalyst particles are concealed by ionomer. (b) $\mathrm{ACV}=0.3 \mathrm{kV}$. All catalyst particles are concealed by ionomer. 
Field Emission Scanning Electron Microscope (FE-SEM), or HR-SEM, with retarding function or TEM with element analysis or TEM with a cryo-system to decrease the damage of organic ionomer on catalysts by electron beam are reported. Figure 13 shows the existence of non-uniform coverage of ionomer. Conventionally, the rod like micellar structures or their aggregates in diluted perfluorinated ionomer solutions were proposed as a tentative image based on the analysis by Small Angle X-ray Scattering (SAXS) and Small Angle Neutron Scattering $(\text { SANS })^{53)}$ or Dynamic Light Scattering (DLS). The concentration of ionomers in catalyst ink is much higher than in their basic studies. Gaining information about the practical concentrated dispersion of ionomers instead of diluted ones is needed. The structure of ionomer dispersions in over $1 \%$ ionomer solution was analyzed on trial recently using Ultrasonic Attenuation Spectroscopy (UAS), $\xi$-potential and laser microscope and anisotropy of dispersed ionomer particles were estimated to be decreased at increased concentration in aqueous and alcoholic solutions. ${ }^{54}$

Water distribution in membrane or single cell has been analyzed by various optical methods, Magnetic Resonance Imaging (MRI) and Neutron Radiography (NRG). Improvement of space resolution under $10 \mu \mathrm{m}$ is expected. The fibrillar structure of PFSA dispersion estimated by SAXS and SANS may render deeper understanding of PFSA membrane structure instead of the conventional Gierke's model. ${ }^{55)}$

As for the chemical stability, the Fenton reagent prepared from $\mathrm{H}_{2} \mathrm{O}_{2}$ aqueous solution and $\mathrm{FeSO}_{4}$ is often used. But it is well known that chemical degradation caused by $\mathrm{H}_{2} \mathrm{O}_{2}$ is most vigorous at the state of open circuit in dry condition. Fenton tests are conducted in aqueous solution. A new method in which humidified $\mathrm{H}_{2} \mathrm{O}_{2}$ gas is introduced into a circumstance controlled chamber has been proposed to simulate the real operated state of PEFC. Degradation mechanism comprised of unzipping of polymer ends and scission of main chains is estimated based on the changes of polymer weight, $\mathrm{F}^{-}$ release and molecular weight.

Advancement in computer simulation founded on molecular orbital method is expected to contribute to deeper understanding of the formation of ionic cluster, protonic conduction, chemical deterioration of membranes and water-uptake over $100^{\circ} \mathrm{C}$, etc.

\section{Concluding Remarks}

Owing to the continuous development and improvement in electrocatalysts, membranes, separators, other materials as well as technical methods for MEA fabrication, the performance of PEFCs and DMFCs have shown remarkable progress. Various new materials and novel evaluation methods have helped to increase the performance, durability, and reliability of components and stacks, in conjunction with reduction in cost. In this headline article, distinctive evaluation methods and specific topics that require attention when using particular evaluation techniques of material have been pointed out. The development of the fuel cell science and technology has been supported by extraordinary efforts of many researchers and engineers from world-wide. Various academic viewpoints and methods are now blending to form a typical interdisciplinary research field.

\section{References}

1) Kotai Koubunshigata Nenryoudenchi no Subete (All about PEFCs) (H. Tamura, H. Uchida, H. Ikeda, C. Iwakura, and Y. Takasu, Eds.), NTS, Tokyo (2003) [in Japanese].

2) J. O'M. Bockris and H. Wroblowa, J. Electroanal. Chem., 7, 428 (1964).

3) M. Watanabe and S. Motoo, J. Electroanal. Chem., 60, 267 (1975).

4) T. Frelink, W. Visscher, and J. A. R. Van Veen, Surf. Sci., 335, 353 (1995).

5) A. Aramata and M. Masuda, J. Electrochem. Soc., 138, 1949 (1991).

6) W. C. Choi, J. D. Kim, and S. I. Woo, Catal. Today, 74, 235 (2002) .

7) T. Kawaguchi, Y. Rachi, W. Sugimoto, Y. Murakami, and Y. Takasu, J. Appl. Electrochem, 36, 1117 (2006).

8) Y. Takasu and X.-G. Zhang, Current Topics in Electrochemistry, 5, 93 (1997).

9) Y. Takasu, W. Sugimoto, and Y. Murakami, Catalysis Surveys from Asia, 7, 21 (2003).

10) W. Sugimoto, H. Iwata, Y. Yasunaga, Y. Murakami, and Y. Takasu, Angew. Chem. Int. Ed., 42, 4092 (2003).

11) W. Sugimoto, T. Saida, and Y. Takasu, Electrochem. Commun., 8, 411 (2006).

12) B. C. Beard and P. N. Ross, Jr., J. Electrochem. Soc., 137, 3368 (1990).

13) T. Toda, H. Igarashi, H. Uchida, and M. Watanabe, J. Electrochem. Soc., 146, 3750 (1999).

14) Y. Takasu, N. Ohashi, X.-G. Zhang, Y. Murakami, H. Minagawa, S. Sato, and K. Yahikozawa, Electrochim. Acta, 41, 2595 (1996).

15) M. Watanabe, H. Sei, and P. Stonehart, J. Electroanal. Chem., 261, 375 (1989).

16) H. Yano, H. Uchida, and M. Watanabe, J. Phys. Chem. B, 110, 16544 (2006).

17) N. Yoshinaga, K. Oohori, W. Sugimoto, and Y. Takasu, Proc. $30^{\text {th }}$ Electrolysis Technology Symposium, Kyoto, Japan (2006) [in Japanese].

18) A. Ishihara, K. Lee, S. Doi, S. Mitsushima, N. kamiya, M. Hara, K. Domen, K. Fukuda, and K. Ota, Electrochem. Solid-State Lett., 8, A201 (2005).

19) H. Morikawa, N. Tsuihiji, T. Mitsui, and K. Kanamura, J. Electrochem. Soc., 151, A1733 (2004).

20) Fuel Cell Characterization Methods (Y. Takasu, M. Yoshitake, and T. Ishihara, Eds.), Kagaku Dojin, Tokyo (2005) [in Japanese].

21) Y. Takasu, T. Fujiwara, Y. Murakami, K. Sasaki, M. Oguri, T. Asaki, and W. Sugimoto, J. Electrochem. Soc., 147, 4421 (2000).

22) H. Uchida, J.-M. Song, S. Suzuki, E. Nakazawa, N. Baba and M. Watanabe, J. Phys. Chem. B, 110, 13319 (2006).

23) T. Kawaguchi, W. Sugimoto, Y. Murakami, and Y. Takasu, J. Catal., 229, 176 (2005).

24) Y. Takasu, R. Unwin, B. Tesche, A. M. Bradshaw, and M. Grunze, Surf. Sci., 77, 219 (1978).

25) Y. Takasu, Y. Matsuda, and I. Toyoshima, Chem. Phys. Lett., 108, 384 (1984).

26) J. Clavilier, R. Faure, G. Guinet, and R. Durand, J. 
Electroanal. Chem., 107, 205 (1980).

27) Y. Takasu, K. Yahikozawa, N. Tateishi, M. Ueno, and Y. Matsuda, J. Chem. Soc. Chem. Commun., 1990, 235.

28) R. Miyoshi, W. Sugimoto, Y. Murakami, and Y. Takasu, Hyomen Kagaku, 23, 503 (2002) [in Japanese].

29) T. J. Schmidt, H. A. Gasteiger, G. D. Stäb, P. M. Urban, D. M. Kolb, and R. J. Behm, J. Electrochem. Soc., 145, 2354 (1998).

30) E. Higuchi, H. Uchida, and M. Watanabe, J. Electroanal. Chem., 583, 69 (2005).

31) T. Kawaguchi, W. Sugimoto, Y. Murakami, and Y. Takasu, Electrochem. Commun., 6, 480 (2004).

32) H. A. Gasteiger, N. Markovic., P. N. Ross, Jr., and E. J. Cairns, J. Phys. Chem., 98, 617 (1994).

33) T. Ioroi, K. Yasuda, and Y. Miyazaki, Phys. Chem. Chem. Phys., 4, 2337 (2002).

34) C. L. Green and A. Kucernak, J. Phys. Chem., 106, 1036, 11446 (2002).

35) Y. Kanzaki, New Collection of Techniques in Electrochemistry (Electrochem. Soc. Jpn., Ed.), p.29 (1988).

36) N. Wakabayashi, M. Takeuchi, H. Uchida, and M. Watanabe, J. Phys. Chem. B, 109, 5836 (2005).

37) M. Itagaki, N. Kobari, S. Yotsuda, K. Watanabe, S. Kinoshita, and M. Ue, J. Power Sources, 35, 255 (2004).

38) E. Ivers-Tiffée, A. Weber and H. Schichlein, Handbook of Fuel Cells, Vol. 2, (W. Vielstich, A. Lamm, and H. A. Gasteiger, Eds.), John Wiley \& Sons, Chichester, Chap.17 (2003).

39) W. Sugimoto, K. Aoyama, T. Kawaguchi, Y. Murakami, and Y. Takasu, J. Electroanal. Chem., 576, 215 (2005).

40) A. Eisenberg and H. L. Yeager, Perfluorinated Ionomer Membranes, Vol. 283, American Chemical Society, Washington, DC (1982).

41) K. A. Mauritz and R.B. Moore, Chem. Rev., 104, 4535 (2004).
42) Japan Society for the Promotion of Science, Hussokagaku Nyuumon, Sankyo Publishing (2004) [in Japanese].

43) M. Doyle and G. Rajendran, Perfluorinated membranes, in Handbook of Fuel Cells (W. Vielstich, et al., Eds.), Wiley, pp.351 (2003).

44) A. B. LaConti, Proc. of the Symposium on Electrode Materials and Process for Energy Conversion and Storage, 77, 354 (1977).

45) D. P. Wilkinson and J. St-Pierre, Handbook of Fuel Cells (W. Vielstich, et al., Eds.), Wiley, pp.612 (2003).

46) N. E. Cipolini, Mater. Res. Soc. Symp. Proc., Vol. 885E, 0885-A01-06

47) Asahi Glass Co., Ltd., http://www.agc.co.jp/ english/news/2004/0928_e.pdf.

48) H. Kodani, M. Wakizoe, and N. Miyake, High temperature membrane with durability for PEFCs, Proc. of International Fuel Cell Workshop 2005, Kofu, p.55 (2005).

49) M. K. Debe, Advanced Catalyst an Membrane Technology with Automotive Requirements, Proc. of International Fuel Cell Workshop 2005, Kofu, p.61 (2005).

50) M. Hogarth and X. Glipa, High Temperature Membranes for Solid Polymer Fuel Cells, ETSU F/02/00189/REP, DTI/Pub URN 01/893.

51) M. A. Hacker, H. Hassam, Y.S. Kim, B.R. Ensile, and J.E. McGrath, Chem. Rev., 104, 4587 (2005).

52) M. Yoshitake, M. Tamura, N. Yoshida, and T. Ishisaki, Denki Kagaku (Electrochemistry), 64, 727 (1996).

53) P. Aldebert, B. Dreyfus, G. Gebel, N. Nakamura, M. Pineri, and F. Volino, J. Phys. France, 49, 2101 (1988).

54) M. Yoshitake, Pre-symposium of TOCAT5 in FukuokaCatalysis in Relation to Fuel Cell Technology, Abstr. Fukuoka (2006).

55) T. D. Gierke, G..E. Munn, and F.C. Wilson, J. Polymer Sci., 19, 1687 (1981). 